\title{
Option-based tasks: an effort to encourage the efl students to learn
}

\author{
Tono Suwartono \\ Faculty of Teacher Training \\ Universitas Muhammadiyah Purwokerto, Indonesia \\ suwartononewton@gmail.com \\ Nina Fivi Oktavia \\ Sekolah Tinggi Ilmu Ekonomi Muhammadiyah Cilacap, Indonesia \\ ninafivi95@gmail.com
}

\begin{abstract}
Teaching is to create environment for students to learn. However, there are times when students become reluctant to learn. One reason is the given learning tasks are irrational. A good example in the ELT context is a common reading comprehension class in which the teacher gets the students to produce oral or written answers to a series of 'wh' questions that follow a reading passage. It is too demanding. This paper aims to propose EFL learning tasks that adopt (or adapt) option-based techniques in an attempt to facilitate students' learning. The paper begins with the rationale behind the adoption of each technique. Then, it discusses things to consider when preparing the tasks. A selected sample of such techniques for ELT will be presented in the last part of the paper.
\end{abstract}

Keywords : Option-base tasks, ELT, techniques

\section{Introduction}

This paper is based genuinely on the writer's ideas, expriences as a teacher trainer and partly on his survey. In Indonesia, the EFL learners' proficiency is generally low. It is likely to have something to do with the teachers' low competence and/or performance. As we all know, a teacher is a classroom facilitator. However, unfortunately, according to the writer's survey study, in relation with the classroom activities, the teachers practising peer-teaching during in-service training in the teacher certification program were poor in the use of teaching media, did not offer appetizing learning activities, and used no hand-outs but one particular book at hands. Most of the lesson time was spent by the students listening to the teacher and writing few points (Suwartono, 2009). The situation is in line with what Bjork (2013: 53) criticised as follows. "I was surprised by what I saw. Teachers tended to lecture from a stationary position at the front of the room, or to transribe large sections from textbooks onto the blackboard". Further he criticised more specifically about teacher trainings in Indonesia that "lack models of effective practice and challenged by large class sizes" and the trainee teachers or teachers that "tend to spend most of their time lecturing, and expect pupils to take responsibilities for mastering the curriculum" (2013: 56). When being introduced to something new, they seemed to find it hard to accept it. In addition, questions and signs of denial frequently arose when coming to the idea of full use of target language in the EFL education. It has been not easy to ensure the teachers that discussing new words of the text after whilst-reading activity is better than that done prior to whilst. They hardly believed that this sequence was beneficial to the learners instead.

The global image is that the condition above is rooted from the practice of teacher-centered education which remains persistent at all levels in many places. This could be seen from the teaching performance of the student teachers, at least because they were trained by the classroom practitioners at the schools. Some teachers gave the trainees a chance of sitting in the classroom for observation before they started to practice conducting a lesson. In the meantime, informal dialogues with students of primary schools (when they attended home-tutoring) indicated their English teachers had rarely given home assignments, feedbacks, and were often absent.

In the matter of task, in task-based language teaching, the focus is on the completion of the task (Huang, 2010). However in this case, the tasks given for students' activities in most of the time were similar pattern - therefore monotonous, and frequently too demanding. They did not seem to be able to make these classroom activities "delicious menu" that would always drive the students to learn. Whereas according to Ellis (2004:9), actually, a task should require "learners to use language, with the 
emphasis on meaning, to attain an objective, and which is chosen so that it is most likely to provide information for learners and teachers which will help them in their own meaning" By doing so, it is hoped that EFL students are encouraged to take risks and participate (Hashemi, et. al. 2012). Up to this point, creativity plays a vital role. The rest of the paper will deal with option-based tasks as a form of teacher creativity in an attempt to facilitate the students' learning.

In this paper, techniques usually used for testing are adopted (or adapted) for instructional purpose. It is an ordinary thing that the so-called close-procedure, pultiple-choice, matching and gap-filling is used in language testing and educational evaluation. Here, however, these testing techniques are empowered to help students learn.

\section{The Rationale Behind the Adoption of Each Technique}

Teaching is basically to create an environment for students to learn. The environment provided is certainly the one that sooner or later leads to learning sustainability. One important aspect necessarily taken into account for this is an image in the eyes of the students that learning is interesting. The teachers should be able to make learning something that they do not want to miss. This can be achieved by avoiding monotonous activities and too difficult tasks. Option-based tasks are a recommended alternative. Many language learning activities, mainly those related to receptive language skills and knowledge, can be presented using option-based tasks. Generally speaking, with options the students have choice. With choice they feel secure. This is why it is quite possible that difficult and challenging tasks become simple rather than demanding. In other words, this type of tasks is likely to make the students enjoy going through the given tasks, away from feeling stressed. This above all saves time - that means more learning activities and/or reinforcement can be covered.

Perhaps, the commonest issue for option-based procedures is reliability - the likelihood of choosing a correct answer by chance. It is true in the context of evaluation. In the context of teaching and learning process, however, it is not a matter. On the other hand, it can be even intentionally made for facilitating learning. In order not to worry about students' seriousness in doing the tasks the teacher can once in a while ask the students to propose supporting ideas by signalling (underlines, circles) at or inserting to (the provided spaces) the parts of learning materials they think of as clues for choices. This will be discussed in more detail later under 'Things to Consider when Preparing the Tasks' section:

\section{Multiple-Choice Technique}

One important aspect of a language is vocabulary. There is no language acquisition and learning without vocabulary development. In the context of EFL learning, option-based tasks will surely help learners develop the target language vocabulary. This of course requires the teacher's intervention in order to facilitate learning. Take, for instance, to help students search for meaning of new words found in authentic materials, the teacher can provide the students with options that include both key and distracters they are already familiar with. By doing so, the teacher helps the students find meanings without telling them directly. This somehow supports inquiry learning.

In helping the students arrive at meaning, a vocabulary development employing multiple choice exercises is an alternative technique to avoid shift to mother tongue, which means communicativeness is maintained, linguistic input/exposure is supported, and students are made to stay tuned. They sooner or later will see the need to follow the content being spoken or written in the target language during the lessons. Too much use of mother tongue will only make them neglect it.

By manipulating the options (e.g. that include familiar words/longer linguistic units), the teacher gets the students to practice known linguistic items. It is a good practice as it can recall inactive vocabularies which are otherwise likely to be forgotten.

In daily Engish classroom practices, multiple-choice can also be used to help students learn to comprehend a text properly. For example, it has been a long tradition that questions which require longer responses follow the reading passages (most noticeably essay). It is, of course, monotonous and to many students essay items perhaps seem demanding and can lead to reluctance to learn. Multiple-choice questions, however, can be suitable approach to reading or listening comprehension classroom tasks and/or home exercises. In the first place, since the response is limited, multiple-choice questions enable the students to focus on meaning. Covering things other than perception of meaning in reading (and listening) comprehension tasks would seem unfair! And this will happen if students have to give 
written or oral responses (productive). In the second, it is likely that the students will be encouraged to read the texts, as they have options, which let them feel having less risk. Even at times, when intended, the options can serve as assistance for text comprehension, meaning that students do not have to always go from text to questions.

Instead of those benefits pointed out above, this technique has been so far known in the area of testing only.

\section{Matching Technique}

As far as vocabulary building is concerned, it is a very good idea to use matching exercises. In its appearance, this technique looks like a puzzle; and therefore, attractive. Students spontaneously draw lines connecting entries within both columns. Included in this technique is completion exercise in which options are provided in the box, identifying pictures while listening, and sticking labels under pictures. What might be matched might include synonymous words, antonyms, words and definitions, words and pictures, etc.

\section{Binary Technique}

This technique is uncommon in testing. One reason is that it gives too much possibility to the candidates for being right by guessing. However, it is because of this reason this technique is expected to give its contribution to the teaching of EFL. With this procedure students are likely to find clues while trying to comprehend spoken texts too fast for them, or written texts too hard for their level. In addition, with this technique the students spend less time giving the response, because they just, for example, check the box before each option. Included in this technique are (S)ame - (D)ifferent, (T)rue - (F)alse, and other binary questions often found in listening skill exercises as can be seen below:

\begin{tabular}{|c|c|c|}
\hline \multicolumn{3}{|c|}{ Listen and circle the words you hear } \\
\hline $\begin{array}{l}\text { 1. a. sheep } \\
\text { b. cheap }\end{array}$ & $\begin{array}{l}\text { 4.a. cherry } \\
\text { b. sherry }\end{array}$ & $\begin{array}{r}\text { 7.a. share } \\
\text { b. chair }\end{array}$ \\
\hline $\begin{array}{l}\text { 2.a. chips } \\
\text { b. ships }\end{array}$ & $\begin{array}{l}\text { 5.a. sheep } \\
\text { b. cheap }\end{array}$ & $\begin{array}{r}\text { 8. a. cherry } \\
\text { b. sherry }\end{array}$ \\
\hline $\begin{array}{l}\text { 3. a. share } \\
\text { b. chair }\end{array}$ & $\begin{array}{l}\text { 6. a. chips } \\
\text { b. ships }\end{array}$ & \\
\hline
\end{tabular}

\section{Arranging Technique \\ Organizing ideas might be still difficult to some students. Providing these students with}

jumbled words or sentences is perhaps a good idea. The activity will let the students work through trial and error. This technique might be best for teaching reading comprehensioan. It is quite stimulating, for instance, for many students to be faced with jumbled paragraphs in reading comprehension class. The students are expected to re-arrange them into a good order. But, since it involves idea organization, it is of great value to use it for training productive skills as well. In a writing class, sequencing could be a good step to take for writing competence development.

\section{Categories}

In a reading comprehension class, a teacher trainee began with an activity which was exciting enough to the students. She split the board into three parts and labelled each with a category name. The students were invited to attach cards (on which a word was written) they received under the most possible category. The students looked very active. In turn, they went to the front to be volunteers. Ur and Wright (1992) call this kind of activity as 'category'. It is a game that they consider powerful for teaching listening comprehension or writing of isolated words.

With the options already available, the responses expected are narrowed. Consequently, the activity made the students learn with no or just little burden. Another advantage of doing such an activity is that the students activate what they have learned. Generally speaking, this type of tasks is good to form associative links between different things. Included in this type of task is odd one out, e.g.

$\begin{array}{lll}\text { chair } & \text { table } & \text { window } \\ \text { cupboard } & \text { desk } & \text { shelf }\end{array}$

It might be used satisfactorily to start a speaking class because it is provoking. Instant arguments can be expected from the students when making association or comparison.

\section{Things to Consider When Preparing the Tasks}

In general, preparing option-based tasks for instructional purpose does not have to follow strict rules that are imposed on assessment test. While in a test battery a multiple choice question is considered poor because one of the options appears extreme, this might not be a problem so much in learning tasks. The inclusion of more than one acceptable 
answer is still possible here, because discussion might follow shortly after the students do the task. Even, in the use of multiple-choice questions for learning exercises the teacher can manipulate the options in such a way that the students will find a clue. When four-option questions are employed. For example, four words presumably familiar to the students are then chosen, but three are made impossible to the question stem. So, this needs a touch of crativity in the part of teacher.

While it is considered a must to provide a few wxtra options as distracters in matching tests, in the context of teaching and learning both questions and options may be set in an equal number. It is intended to case the way for the students to match the entries. As is the case of multiple-choice, the modified matching exercises can be a brilliant technique for giving students clues, or teaching something new. In an English teachers training peer-teaching session most of the "students" were complaining when they received the task sheet. They said they never had seen the Rafflesia before. It would not have happened if the "teacher" had not apparently just copied the material. The conversational material contained 4 blanks. The options provided, however, were doubled.

Fill in the blanks with the words provided
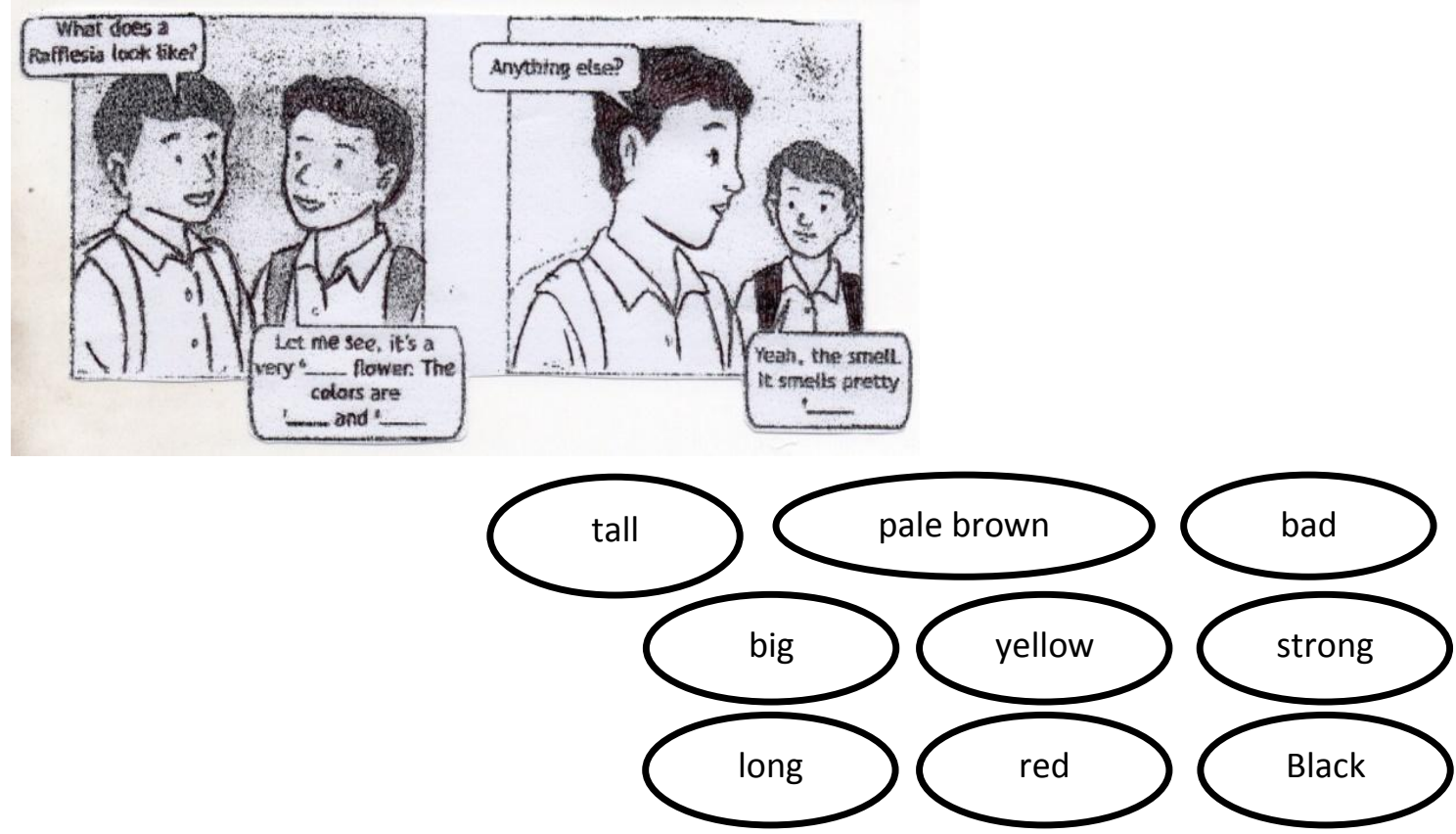

Some exercises adopting this technique use option numbering. It is allright in receptive skills training or linguistic knowledge development. However, for productive language skills instructional objectives, indeed the absence of numbering is advisable in order to prevent the students from mentioning only the numbers or letters. The task below belongs to matching technique. But since many of the entries are minimal pairs or nearly minimal pairs, binary technique may be more suitable.

$\begin{array}{lllll}\text { live } & \text { love } & \text { rest } & \text { still } & \text { book } \\ \text { life } & \text { talk } & \text { rich } & \text { steal } & \text { hook } \\ \text { afraid } & \text { attend } & \text { reach } & \text { fight } & \text { village } \\ \text { asleep } & \text { send } & \text { curse } & \text { give } & \text { kingdom } \\ \text { sleep } & \text { arrest } & \text { course } & \text { gift } & \end{array}$


The major threats to reliability of binary techniques are perhaps the lack of clarity and the wild speculation in the part of students. That is why prior to implementation the teacher should make sure that the statements used (usually ranging from words to sentences) do not lead to misinterpretation or confusion. In the meanwhile, to ensure students' seriousness in doing the tasks the teacher can once in a while ask the students to suggest supporting ideas by, for example, underlining the learning materials or inserting key words in the spaces provided. When working with good EFL learners, it is wise for the teacher to provide paraphrases instead of quotes.

Students may find it hard to do arranging task. This may result from the lack of clues and length of text. Within sime genres, such as narrative and procedural texts, or conversational texts, clues are often easy enough to find out. When clues are rare, it is safer to provide students with smaller number of entries. However, in general, shorter texts might look more hospitable to students. Blunders such as badly jumbled entries or unevenly-cut slips of paper (on which a text is written) should be avoided. The following task is irrational and too demanding. The Primary School level students will find it hard to rearrange the letters while listening. When a listening task is intended, matching technique will be a good choice. The students are supposed to choose answers by, say, for example, numbering the pictures. Rearrangement of the jumbled letters could be set for a writing task separately from the listening task.

\section{A. Listening}

\section{Task 1}

\section{Listen to the teacher and then arrange the jumbled letters based on the pictures!}

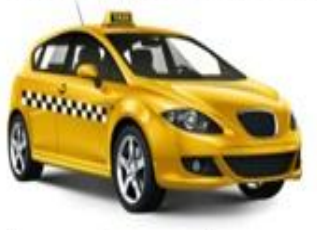

1. $\mathrm{x}-\mathrm{i}-\mathrm{a}-\mathrm{t}$

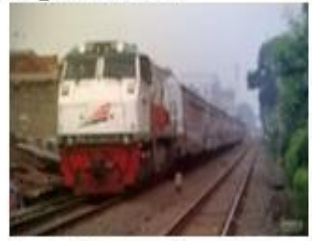

2. $n-i-t-a-r$

Allswer:

Allswer:
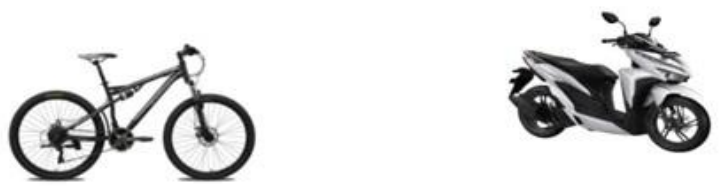

3. $\mathrm{c}-\mathrm{y}-\mathrm{i}-\mathrm{e}-\mathrm{b}-\mathrm{i}-\mathrm{c} 4 \mathrm{c}-\mathrm{c}-\mathrm{m}-\mathrm{y}-\mathrm{o}-\mathrm{c}-\mathrm{t}-1-$ $\mathbf{o}-\mathbf{e}-\mathbf{r}$

Allswer:

Allswer:

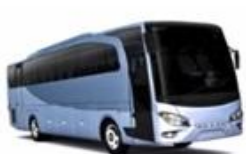

5. $s-\mathbf{u}-\mathbf{b}$

p-o-c

Aliswer:

Allswer:
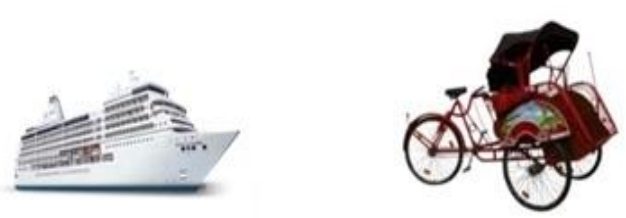

7. h- i - p - s

8. $i-e-p-c-a-d-p$
Allswer:

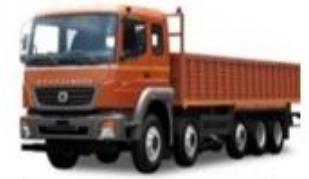

9. $\mathrm{c}-\mathrm{t}-\mathrm{u}-\mathrm{r}-\mathrm{k}$

$-\mathbf{r}-\mathbf{a}-\mathbf{c}$

Allswer:

Allswer:

In preparing a categories task, one crucial consideration is the students' level. Since options do not affect each other or one another in this technique, except One Odd Out, selected proper categories or items would possibly be to the students' taste. When the given tasks offer categories and/or items totally new to their level, the students would lose their interest, as they can rely solely on familiarity. 
Examples of the Techniques in the Context of ELT

\section{Multiple-choice technique for teaching reading comprehension}

Read the following text and answer the questions

I went to China for 3 weeks and it was an eye-opening experience. First of all the City of Beijing is simply huge with hundreds of tall apartment buildings in every direction. The roads and highways are wide and very clean with gardens and shrubs each side of the road. Traffic was not as chaotic as in many other large cities. The majority of cars and buses that I saw were new models, with very few cars older than a few years.

The word 'chaotic' in line 4, paragraph 1 is closest in meaning to .....
A. uninteresting
C. impossible
B. disorganized
D. misunderstood

To most Indonesian Secondary School students of $\mathrm{EFL}$, there are several new words/phrases in the text above, including eye-opening, simply, huge, highways, shrubs, and chaotic. Among these words, perhaps all but chaotic is the most difficult one. The neighbouring words alone cannot lead the students to the substitute for sure. In a reading comprehension class, with quite rare clues for a difficult word like this a teacher can still help the students by using multiple-choice questions with more 'identifiable' key and distracters. In the example above, when the teacher assumes that the words set in all option are familiar to or will be most probably detected by the students, and that A, C, and $\mathrm{D}$ are intentionally made impossible; he can expect much that the students will choose B as the answer and therefore acquire a new vocabulary item together with its synonyms.

And now let's suppose the students have got limited clues from the text below, e.g. 'year' and 'to the old', because the familiar words such as 'happy', 'wonderful', and 'warm' can be misleading (the words might give positive sense; and therefore reject option $\mathrm{A}$ ), the following multiple choice question may be helpful to the students in that both the key and distracters proposed are all presumably recognized by the students (with reference to syllabus/curriculum) and at the same time B, C, and $\mathrm{D}$ are made totally impossible. The students are introduced to the new word 'adieu'.

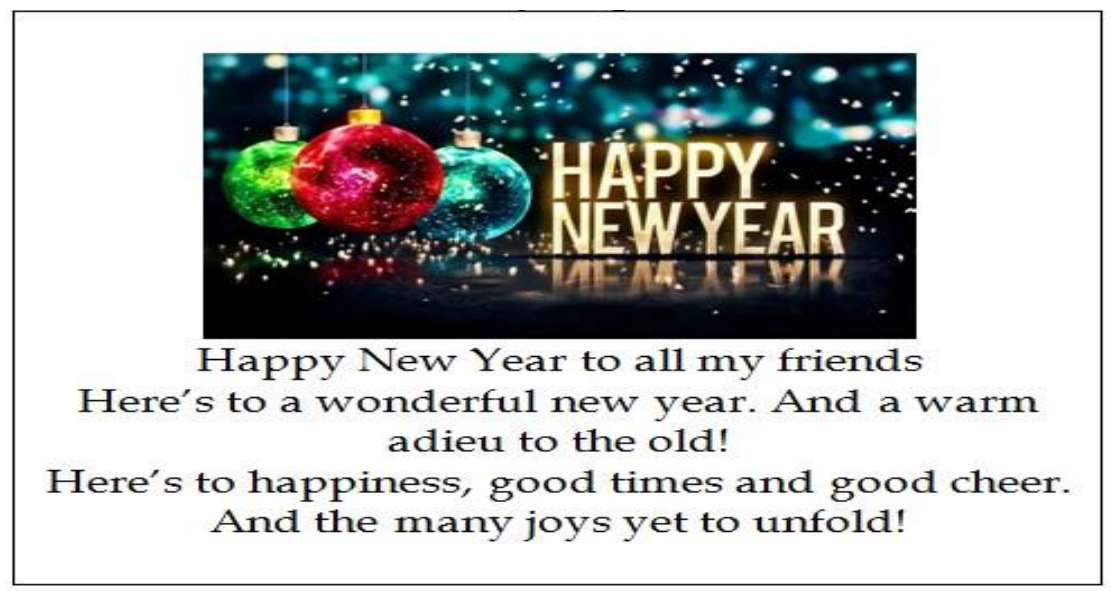

The word 'adieu' in the text can be best replaced with ...
A. goodbye
B. sunlight
C. Spring
D. night 

True or false? If it is false, correct it. Say the correct fact to the class.

1. Calon Arang had a son

False. Calon Arang did not have a son. She had a daughter.

2. People were afraid of Ratna Mangali.

3. Nobody wanted to marry Ratna Mangali because she was not pretty.

4. Calon Arang was angry because nobody wanted to marry her daughter

5. Calon Arang killed the villagers.

6. The king sent his men to arrest Calon Arang.

7. Mpu Baradah was Mpu Bahula's teacher.

8. Mpu Bahula married Ratna Mangali because he loved her.

9. Mpu Bahula asked Ratna Mangali to steal her mother's magic book.

10. After losing her book, Calon Arang became powerless.

\section{Matching Technique for Teaching Vocabulary}

Draw lines to connect the words in A with the definitions in B

\begin{tabular}{|l|}
\hline \multicolumn{1}{|c|}{$A$} \\
1. nationality \\
2. district \\
3. multiculturalism \\
4. religion \\
5. community \\
\hline
\end{tabular}

B

a. a smaller part of town

b. group of people

(who share interest)

c. citizenship

d. many different

cultures

e. system of belief

\section{Matching Technique for Teaching Vocabulary}

Complete the sentences with the following words

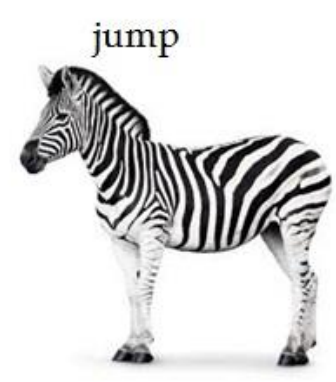

A zebra can .....

A snake can ......

A penguin can ....

A frog can .........

The word 'slither' is new to the ninth graders of primary education in Indonesia. But, the word can succeessfully be introduced to them using this
Let us suppose, a teacher of English has been thinking about the word "religion" as a potential problem to the students in his reading class, he can prepare and use the exercise above to introduce the word successfully, provided the other words listed are assumed to be fully recognized. This exercise can be either included in the whilst-reading activity or presented only when a student asks the meaning. swim

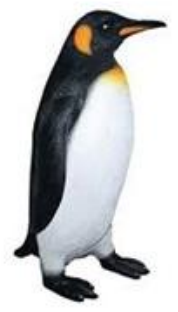

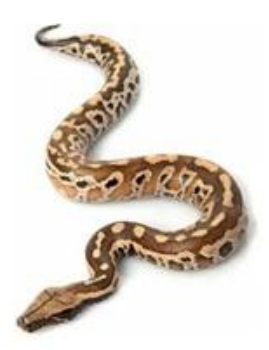

slither

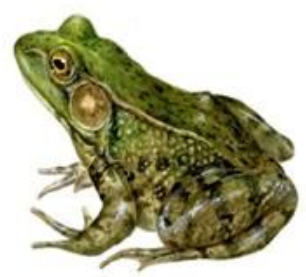

matching technique. The other three words (jump, run, and swim) are already familiar, though usually limited in their relation with human. As the concepts also apply to animals, this task is simple enough to complete. So, the students finally find 'slither' the way hoe a snake travels. 
Matching Technique for Teaching Lstening comprehension:

Listen to the song and number every line you hear Edelweiss

(...) Bless my homeland forever

(...) Every morning you greet me

(...) Edelweiss, edelweiss
(...) Blossom of snow may you bloom and grow

(...) You look happy to meet me

(...) Bloom and grow forever

(...) Edelweiss, edelweiss

(...) Small and white, clean and bright

(...) Edelweiss, edelweiss

\section{Arranging Technique for Teaching Reading Comprehension}

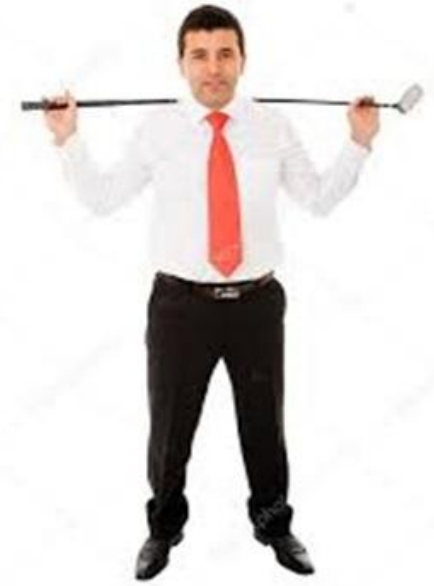

\section{Mr. Smith, an Ordinary Lawyer}

..... At weekends, he and his wife sometimes play golf but that doesn't happen very often. They never have much time to relax together.

.... Mr. Smith is married and he has a daughter, aged 17. His wife works for an NGO (Non-Government Organization). They has a beautiful house in Semarang. It's a big house with eight bedrooms. He is rarely home because so much of his time spent at his office or travelling.

.... Mr. Smith is a lawyer. He is paid very well, but he usually has to work long hours. He works for a national company in Jakarta so he travels a lot in his job. At the moment, he is working on a case in Kendari

\section{Arranging Technique for Teaching Writing:}

Write adjectives from these jumbled letters. The initial letter has been given as a clue

\begin{tabular}{|c|c|}
\hline 1. ticaev & : active \\
\hline 2. iteblufau & : b.................... \\
\hline 3. norgst & :s... \\
\hline 4. gelar & \\
\hline 5. lamsi & \\
\hline
\end{tabular}

\section{Conclusion}

This paper mentions techniques that are believed to give potential benefits to the students when adopted and/or adapted for EFL teaching and learning process. These technniques, which are all option-based, are a reflection of creativity in the part of teacher. Many others might be equally good or better for arousing students' learning interest, but still waiting for teachers' wisdom. Of course, this requires EFL teachers' commitment to their profession.

\begin{tabular}{|c|c|}
\hline 6. kard & :d d..................... \\
\hline 7. ikcht & : t........................ \\
\hline 8. lentsi & : s....................... \\
\hline 9. lexelntce & : e........ \\
\hline 10. orths & : s........................ \\
\hline 11. 1lta & : t......................... \\
\hline 12. dlo & : о......................... \\
\hline 13. ngyuo & : у....................... \\
\hline 14. yttpre & : p \\
\hline
\end{tabular}

\section{References}

Bjork, Christopher. 2013. “Teacher Training, School Norms and Teacher Effectiveness in Indonesia", in Suryadarma et.al. (Eds.). Education In Indonesia (p53, 56). Singapore: Institute of Southeast Asian Studies Singapore

Ellis, Rod. 2004. Task-based Language Learning and Teaching, Oxford: Oxford University Press 
Leksika Vol.13 No.1 - Feb 2019: 46 - 54

Hashemi, M. et. al. 2012. “Using Task-Based Language Teaching: Learning Practically in English Classes", Procedia - Social and Behavioral Sciences

Huang, Jiuhan. 2010. “Grammar Instruction for Adult English Language Learners: A Task-based Learning Framework", Journal of Adult Education, v39 n1 spec iss p29-30

Suwartono, 2009. "The Necessity of Synchronizing the EFL Teachers' Perception with Their Behavior to Upgrade Professionalism". The 1st COTEFL International Conference (Proceeding)

Suwartono, 2007. "A Good Teacher of EFL Speaks the Language in the Class", The 55th TEFLIN International Conference 2007 (Conference Proceedings)

Suwartono, 2008. "Dependent Upon Teacher's Creativity", GloCALL 2008 - Indonesia: Globalization and Localization in CALL (Program Book)

Ur, P, \& Wright. A., 1992. Five-Minute Activities: Resource Book of Short Techniques, Cambridge: Cambridge University Pres 